University of Nebraska - Lincoln

DigitalCommons@University of Nebraska - Lincoln

Papers in Virology

Papers in the Biological Sciences

September 2004

\title{
Preserved antigenicity of HIV-1 p24 produced and purified in high yields from plants inoculated with a tobacco mosaic virus (TMV)- derived vector
}

D. M. Pérez-Filgueira

University of Nebraska - Lincoln

B. P. Brayfield

University of Nebraska - Lincoln

S. Phiri

University of Nebraska - Lincoln

M. V. Borca

Plum Island Animal Disease Center, USDA, Greenport, NY 11944, USA

Charles Wood

University of Nebraska - Lincoln, cwood1@unl.edu

See next page for additional authors

Follow this and additional works at: https://digitalcommons.unl.edu/bioscivirology

Part of the Virology Commons

Pérez-Filgueira, D. M.; Brayfield, B. P.; Phiri, S.; Borca, M. V.; Wood, Charles; and Morris, Thomas Jack, "Preserved antigenicity of HIV-1 p24 produced and purified in high yields from plants inoculated with a tobacco mosaic virus (TMV)-derived vector" (2004). Papers in Virology. 1.

https://digitalcommons.unl.edu/bioscivirology/1

This Article is brought to you for free and open access by the Papers in the Biological Sciences at DigitalCommons@University of Nebraska - Lincoln. It has been accepted for inclusion in Papers in Virology by an authorized administrator of DigitalCommons@University of Nebraska - Lincoln. 


\section{Authors}

D. M. Pérez-Filgueira, B. P. Brayfield, S. Phiri, M. V. Borca, Charles Wood, and Thomas Jack Morris 


\title{
Preserved antigenicity of HIV-1 p24 produced and purified in high yields from plants inoculated with a tobacco mosaic virus (TMV)-derived vector
}

\author{
D.M. Pérez-Filgueira ${ }^{\mathrm{a}, \mathrm{c}, *}$, B.P. Brayfield ${ }^{\mathrm{a}}$, S. Phiri ${ }^{\mathrm{a}}$, M.V. Borca $^{\mathrm{b}}$, C. Wood $^{\mathrm{a}}$, T.J. Morris ${ }^{\mathrm{a}}$ \\ a School of Biological Sciences, University of Nebraska, Lincoln, NE 68588-0118, USA \\ ${ }^{\mathrm{b}}$ Plum Island Animal Disease Center, USDA, Greenport, NY 11944, USA \\ ${ }^{\mathrm{c}}$ CONICET, Av. Rivadavia 1917, 1033 Buenos Aires, Argentina
}

Received 3 March 2004; received in revised form 2 June 2004; accepted 29 June 2004 Available online 25 August 2004

\begin{abstract}
Production of structural proteins from foot-and-mouth disease virus (FMDV) and bovine herpes virus (BHV-1) in Nicotiana benthamiana through the use of a tobacco mosaic virus-based vector (TMV-30B) has been reported previously. The development of the TMV-30B-HISc vector, a new version that adds a C-terminal histidine (His) sequence to the foreign protein expressed is described. Coding sequences from the FMDV VPl protein and the core protein, p24, from a clade C HIV-1 isolate from Zambia were cloned into the new vector and infective RNAs were generated for each construct to inoculate $N$. benthamiana plants. His-tagged proteins were purified from inoculated leaves using immobilized metal affinity chromatography (IMAC) as detected by Coomassie blue staining and proteins were further characterized in Western blot assays using a commercial anti-6xHis $\mathrm{mAb}$ and specific polyclonal antisera for each protein. While yields obtained for the VPl-His protein after purification were similar to those in crude extracts obtained with the previous TMV-VPl vector, p24-His yields were 10-15 times higher than those of VPl-His. Twenty-five grams of TMV-p24-HISc inoculated leaves were processed to obtain 2.5 mg of isolated p24-His and the recombinant protein was inoculated in rabbits to test immunogenicity and antigenic integrity of the plant-produced p24-His. Animals developed a strong and specific humoral response to the p24-His after the first booster and immune sera was able to recognize the native p24 from a different clade expressed on the surface of the HIV-1 chronically infected HUT78/ARV T-cell line. Importantly, the recombinant p24-His proved its efficiency by confirming the serology of 117 samples previously tested by two rapid HIV-1 tests, thus representing an excellent alternative for production of highly specific diagnostic reagents for HIV endemic regions in the developing world.

(c) 2004 Elsevier B.V. All rights reserved.
\end{abstract}

Keywords: HIV; Plant expression; Diagnosis; TMV-vector; Immune response

\section{Introduction}

Plants represent one of the main sources of biomass for economical production of recombinant biological products, especially when compared with traditional fermentation or cell culture based methods (Giddings et al., 2000; Kusnadi et al., 1997; Walmsley and Arntzen, 2003). In the recom-

* Corresponding author. Present address: Depto. Biotecnología, INIAMadrid, Ctra. A Coruña Km.7, Madrid 28040, Spain. Tel.: +34 91347 3794; fax: +34913573157.

E-mail address: mperez@inia.es (D.M. Pérez-Filgueira). binant vaccine field, development of transgenic plants for the gene of interest has represented the classical approach over the past 12 years (Mason et al., 1992; Walmsley and Arntzen, 2000). However, foreign proteins can also be obtained in plants by transient expression using plant virusbased vectors, an alternative which presents advantages over constitutive expression from a transgenic plant (Lacomme et al., 1998). Vectors have been developed utilizing several different groups of plant viruses, with positive single stranded RNA (ssRNA) viral vectors being the most common (Pogue, 2002; Johnson et al., 1997). Some advantages of small ssRNA viruses include small genomes that can be easily 
manipulated from cDNA clones and the potential to generate high yields of viral protein, up to $10 \%$ of the dry weight of the plant (Siegel et al., 1978). They can be applied to mature plants, avoiding toxicity and potential developmental problems associated with constitutive expression of the foreign protein. In addition, the products can be targeted to different locations to facilitate recovery of the recombinant proteins (McCormick et al., 1999). Those derived from members of the Tobamovirus group (tobacco mosaic virus, TMV) are among the most successful applications of this technology (Yusibov et al., 1999). TMV-based vectors, first developed 15 years ago, have since been modified to improve stability and permit enhanced expression of foreign genes (Toth et al., 2002). We have previously utilized the TMV-30B vector (Shivprasad et al., 1999) to express proteins of antigenic relevance for possible use as vaccines against foot and mouth disease virus (FMDV) (Wigdorovitz et al., 1999) and bovine herpesvirus-1 (BHV-1) (Pérez-Filgueira et al., 2003). However, similar studies conducted for other foreign proteins, presented problems with reliable quantification and specific immuno-detection of the recombinant products in the plant extracts, due to background problems resulting from crossreactivity of the viral antiserum with plant proteins. Here we describe a simple modification we made to the TMV-30B vector to overcome these problems and its practical application in a very relevant model as human immunodeficiency virus type 1 (HIV-1).

The new vector, designated TMV-30B-HISc, was constructed so that seven histidine (7xHis) residues would be appended to the $\mathrm{C}$-terminus of the foreign insert. Addition of this $7 \mathrm{xHis}$ tag would not only permit a one-step purification of the foreign protein by immobilized metal affinity chromatography (IMAC) (Nilsson et al., 1997), but it would also facilitate quantification and a more reliable detection of recombinant proteins in Western blot assays using a commercially available monoclonal antibody against the His sequence. To test the system, the VP1 open reading frame (ORF) from the FMDV O1 Campos strain was introduced into the modified vector to directly compare the production and recovery of the recombinant VPl-His protein with the VP1 produced with the original TMV-30B vector previously reported (Wigdorovitz et al., 1999).

The new His-tagged vector was also tested for economical production of the p24 ORF from HIV-1, as this protein was stably expressed in plants previously (Zhang et al., 2000, 2002) and based on our specific need to generate large quantities of the protein for routine diagnostic testing of clade C HIV-1 in sub-Saharan Africa. The p24 capsid protein of HIV-1 is a major component of the gag polyprotein and is an important early marker of HIV-1 infection. Consequently, this protein is routinely included in commercial assays for diagnosing HIV-1 infection. In addition, the World Heath Organization and Centers for Disease Control recommend that Western blot confirmatory tests for HIV-1 infection must detect antibodies to 24 capsid protein among other viral proteins. Epitope mapping studies with HIV-1 have shown that p24 contains several cytotoxic T lymphocyte (CTL) epitopes that are important for immune control of HIV-1 infection (Johnson et al., 1991; Novitsky et al., 2002) and strong CTL responses have been shown to be necessary for successful vaccination in primates (Amara et al., 2001; Barouch et al., 2001; Shiver et al., 2002). Taken together, it is evident that p24 is an important antigen for controlling HIV-1 infection, it can be used in reliably and accurately diagnosing HIV infection, and more importantly, it can be included potentially in a preventive vaccine (Lefrere et al., 1992; Benson et al., 1999).

The results presented below show that the TMV30B-HISc vector represents a very useful tool for transient expression of foreign antigens in plants, allowing facile detection, purification and quantification of recombinant products. Antigenic features of the original p24 were preserved in the recombinant version. The plant-produced $\mathrm{p} 24-\mathrm{His}$ was able to induce antibodies in rabbits that recognized the native p24 in cell cultures and Western blot assays based on the recombinant p24-His presented, for all the samples, concordant results with two other commercial assays. Our results also suggest that this approach offers a very inexpensive means for producing antigens and diagnostic reagents in plants. Estimations based on this confirmatory Western blot test and on the yields of purified p24-His shown here indicate that the recombinant $\mathrm{p} 24-\mathrm{His}$ obtained from $25 \mathrm{~g}$ of fresh leaves would be sufficient to conduct over 20,000 individual assays.

\section{Materials and methods}

\subsection{Plasmid constructions}

To introduce the $7 \mathrm{xHis}$ tag into the TMV-30B vector, a fragment containing the ORF from the FMDV/O1 Campos VP1 was amplified by PCR from the TMV-VP1 plasmid (Wigdorovitz et al., 1999). The direct primer was used to introduce a Pac I site upstream of the VP1 start codon and the reverse primer was designed to introduce, from $3^{\prime}$ to $5^{\prime}$, the Xho I and Pme I sites, and the 7xHis in frame with the $3^{\prime}$ end of the VP1 ORF. The $704 \mathrm{bp}$ PCR fragment was cloned into the TMV-30B vector (Shivprasad et al., 1999) using the Pac I and Xho I sites of the vector polylinker. The resulting TMV-VPIHISc plasmid was digested with Pac I and Pme I enzymes to liberate the VP1 ORF and produce an open plasmid containing the TMV-30BHISc vector. The p24 sequence was amplified from genomic DNA isolated from peripheral blood mononuclear cells (PBMC) of an HIV-1 infected Zambian patient through two rounds of PCR using nested primers. The final 715 bp PCR product contained the Pac I and Pme I sites at the $5^{\prime}$ and $3^{\prime}$ ends, respectively. These restriction sites were utilized to clone the p24 fragment into the open TMV-30BHISc vector to produce the TMV-p24-HISc plasmid (Fig. 1). Constructs were sequenced to confirm correct insertion of the foreign ORFs and integrity of the reading frames. 


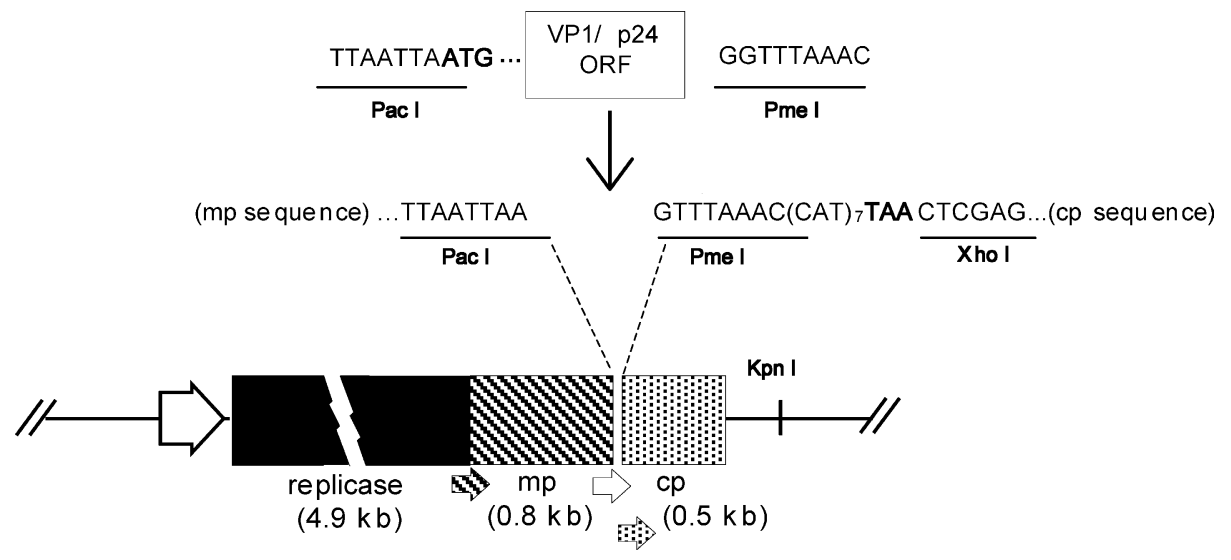

Fig. 1. Schematic diagram of the TMV-30B-HISc vector. VP1 and p24 ORFs were amplified by PCR carrying the Pac I and Pme I restriction sites and cloned in frame with $7 \mathrm{xHis}\left[(\mathrm{CAT})_{7}\right]$ and the stop codon of the vector. Small arrows indicate subgenomic promoters for the movement protein (mp), coat protein (cp) and foreign ORF (white arrow). Viral RNA transcripts were obtained after plasmid linearization at the Kpn I site and in vitro transcription was driven from the $\mathrm{T} 7$ promoter located upstream of the $5^{\prime}$ end of the vector's replicase gene.

\subsection{Plant inoculation}

The TMV-VPIHISc and TMV-p24-HISc plasmids were digested with Kpn I to generate linear templates for in vitro production of run-off capped transcripts (Amplicap T7 transcription Kit, Epicentre Technology). Viral RNA was quantified by electrophoresis and approximately $2 \mu \mathrm{g}$ of viral RNA per plant was applied to the upper surface of Nicotiana benthamiana leaves, as previously described (Pérez-Filgueira et al., 2003). Plants were kept in growth chambers $(16 \mathrm{~h} /$ day of light, $29^{\circ} \mathrm{C}$ day temperature, $24^{\circ} \mathrm{C}$ night temperature) and leaves were harvested 7 days post-inoculation (dpi) and frozen at $-20^{\circ} \mathrm{C}$ until processed.

\subsection{Production and purification of recombinant proteins}

Inoculated plant leaves were ground in extraction buffer containing phosphate saline (PBS)/8 M urea ( $\mathrm{pH}$ 8.0). Clarified sap was obtained after passing the ground suspension through a Miracloth filter (Calbiochem) and centrifugation at $15,000 \times g$ for $10 \mathrm{~min}$. IMAC beads (Talon, Clontech) were resuspended in the same extraction buffer and incubated with the clarified sap for $1 \mathrm{~h}$ at room temperature (RT). Beads were then washed three times in PBS/8 M urea $(\mathrm{pH}$ 6.3 ), placed in columns and His-tagged proteins were eluted with $6 \mathrm{M}$ urea/300 $\mathrm{mM} \mathrm{NaCl} / 50 \mathrm{mM} \mathrm{Na}$ acetate using a $\mathrm{pH}$ gradient from 5.8 to 4.8 .

\subsection{Protein analysis}

IMAC elution fractions and bead samples were resolved in duplicate $12 \%$ SDS-PAGE gels for Coomassie blue staining and transfer onto ECL nitrocellulose membranes (Amersham). For Western blot analysis, membranes were blocked overnight with PBS-tween 20 (PBST) containing 4\% skim milk, and subsequently incubated at room temperature (RT) with a primary antibody-specific for the recombinant pro- tein and a species-specific HRP-labelled conjugate as secondary antibody. Protein bands were detected using the ECL Western blotting detection system (Amersham) on X-ray film (Kodak). His-tag detection was carried out using an anti6xHis mAb (Clontech) and anti-IgG mouse HRP-labelled conjugate as secondary antibody. Polyclonal mouse serum against the 135-160 amino acid sequence (p135-160) of VP1 FMDV OIC (Zamorano et al., 1994) was used as the primary antibody for VPl detection. A pool of sera from HIV1 positive patients was used as the primary antibody for p24 detection with anti-human Ig HRP-labelled conjugate as a secondary antibody. For re-probing assays, membranes were incubated with a stripping buffer containing Tris- $\mathrm{HCl}$, $62.5 \mathrm{mM} / 2-$ mercaptoethanol, $100 \mathrm{mM} / \mathrm{SDS}, 2 \%$ for $30 \mathrm{~min}$ at $50{ }^{\circ} \mathrm{C}$ and washed with PBS before performing Western blot analysis as described above. The concentration of each recombinant protein was estimated from known bovine serum albumin standards by Coomassie blue staining in conjunction with the BioRad Fluor S Multilmager System and Quantity One 4.0 software (BioRad).

\subsection{Animal immunizations}

Two female rabbits were immunized with the purified recombinant $\mathrm{p} 24-\mathrm{His}$ diluted in elution buffer. The immunogens for the first inoculation were formulated containing complete Freund adjuvant and $0.5 \mathrm{mg}$ of recombinant protein/dose. A second immunization was performed with $0.25 \mathrm{mg}$ of recombinant protein/dose and incomplete Freund adjuvant 15 days post-initial immunization. Rabbits were bled at 30, 45 and 60 days after the first inoculation.

\subsection{Immunofluorescence assay (IFA)}

HUT 78/ARV cells, a human T lymphoma cell line chronically infected with HIV-1, were utilized for detection of antibodies to p24 as previously described (Mantina et al., 2001). 
Briefly, HUT78/ARV cells were spotted onto slides at a concentration of $5 \times 10^{5}$ cells $/ \mathrm{ml}$, air dried and fixed in cold acetone. Slides were sequentially incubated at $37^{\circ} \mathrm{C}$ for $30 \mathrm{~min}$ with rabbit anti-p24 sera, DTAF-conjugated anti-rabbit antibody; and slides were washed with PBS in between incubations. Slides were then incubated with Evans blue (0.004\%) for 3 min to counter stain cells.

\subsection{Rapid qualitative testing and Western blot for HIV-1}

Rapid qualitative testing for HIV was performed with the Determine $^{\mathrm{TM}}$ and Capillus ${ }^{\mathrm{TM}}$ assays according to the manufacturer and as previously described (Abbott Laboratories, Abbott Park, IL; Trinity Biotech, Bray, Co Wicklow, Ireland). Positive test strips were visually determined for each case. Samples with concordant positive results for both rapid tests were considered positive and a subset was subjected to confirmation by Western blot against the HIV-1 recombinant p24-His. Purified plant-produced p24-His was added to preparative gels estimating $0.1 \mu \mathrm{g}$ of recombinant protein per sample lane, resolved by SDS PAGE and Western blotted as described above. Blots were divided in strips and sequentially incubated with the human serum and an anti-human $\mathrm{IgG}$ alkaline-phosphatase conjugate, each for $1 \mathrm{~h}$ at $37^{\circ} \mathrm{C}$. Strips were finally developed with NBT/BCIP substrate and visually analyzed as mentioned for commercial rapid HIV tests.

\section{Results}

\subsection{Expression of FMDV VP1 using the TMV3OB-HISC vector}

Results were described on the production of recombinant VP1 protein (Wigdorovitz et al., 1999) using the TMV-30B vector (Shivprasad et al., 1999). These experiments were repeated here to allow for a direct comparison of the production of VP1 cloned into the TMV-30B-HISc vector. Equivalent amounts of RNA transcript from TMV-30B, TMV-VP1 and TMV-VP1-HISc constructs were inoculated on plant leaves that were harvested at 7 dpi. Protein samples obtained from $25 \mathrm{mg}$ of fresh tissue were compared by SDS PAGE (Fig. 2A) and analyzed by Coomassie blue staining. The TMV coat protein band of $18 \mathrm{kDa}$ is evident in TMV-30B infected sample (lane 3) as expected. A band of expected size for VP1 is not visible in lane 4 (plants inoculated with TMV-VP1) but a faint band in the expected size range (ca. $24 \mathrm{kDa}$ ) is the primary band visible in the TMV-VPI-HISc-derived sample processed with the IMAC beads (lane 6, Fig. 2A). This band was shown to have the expected His-tag by Western blot analysis using the anti-6xHis mAb (Fig. 2B). This IMAC sample, as well as the crude protein extract from the VP1 inoculated leaves, was confirmed to contain approximately equivalent amounts of the VP1 recombinant protein by using polyclonal VP1-antiserum in the Western blot (Fig. 2C). These results clearly show that the one-step IMAC procedure was very effective at purifying the recombinant His-tagged VP1 while still maintaining its antigenic properties. The estimated yield using known protein standards was approximately $6-8 \mu \mathrm{g}$ of VPl-His per gram of fresh plant tissue.

\subsection{Expression of HIV-1 p24 using the TMV3OB-HISc vector}

Leaves were inoculated with the TMV-p24HISc vector as described in the previous section. Production of recombinant p24-His was directly analyzed by SDS-PAGE from the IMAC resin after incubation with a plant sap sample equivalent to $25 \mathrm{mg}$ of fresh leaf inoculated tissue. The stained gel shows a predominant band of approximately $24 \mathrm{kDa}$ and a second band with lower intensity around $50 \mathrm{kDa}$, which is likely a dimer (Fig. 3A). Visual analysis revealed that the amount of recombinant protein isolated from an equivalent amount of plant tissue was considerably higher for p24-His than for VPl-His. Western blot assays confirmed the expected antigenic nature of the two bands isolated from the TMV-p24HISc inoculated leaves. Both the anti-6xHis mAb (Fig. 3B) and HIV-1 specific human antiserum (Fig. 3C) detected the same monomer (ca. $25 \mathrm{kDa}$ ) and suspected dimer (ca. $50 \mathrm{kDa}$ ) bands, confirming the presence of both His and p24 specific antigenic sequences in the proteins.

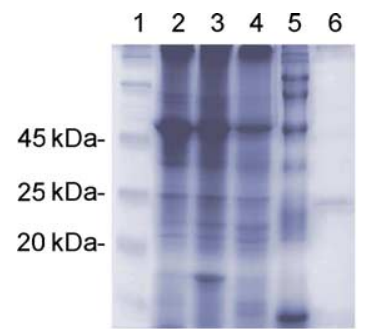

(A)

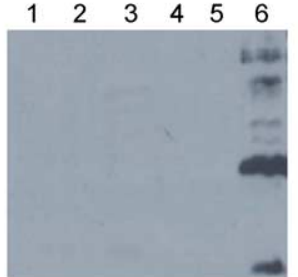

(B)

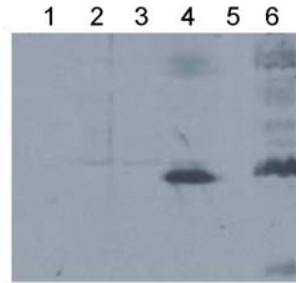

(C)

Fig. 2. Expression of VP1 using the TMV-30B-HISc vector. All protein samples were derived from approximately $25 \mathrm{mg}$ of fresh leaves. Lanes 1 and 5 , two different molecular weight markers (MWM). Panel A: Coomassie blue stained gel of total proteins obtained from a mock infected leaf (lane 2) or leaves inoculated with TMV-30B (lane 3), TMV-VP1 (lane 4) and TMV-VPIHis after MAC binding (lane 6). Proteins in lane 6 derived directly from a sample of the IMAC beads after incubation with the plant sap and washing. Panel B: Western blot from the same gel probed with an anti-6xHis mAb. Panel C: same blot re-probed with a polyclonal mouse antiserum against VP1. 


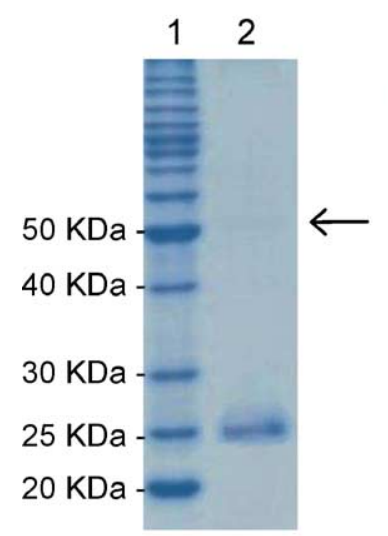

(A)

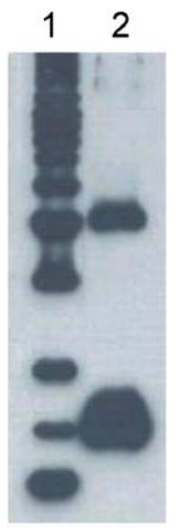

(B)

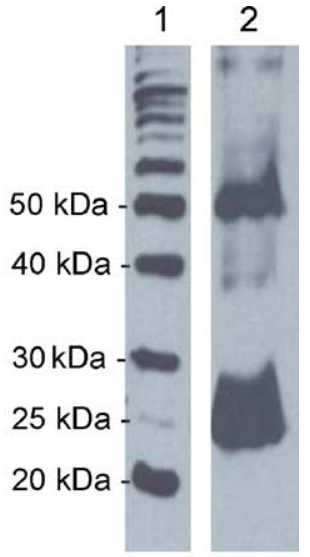

(C)

Fig. 3. Expression of p24-His using the TMV-30B-HISc vector. Panels A-C: Lane 1, His-tagged MW markers; Lane 2, proteins bound to MAC beads after adsorption from plant sap extracted from $25 \mathrm{mg}$ of fresh leaf tissue. Panel A: Coomassie blue stained gel. The arrow indicates the position of a dimeric form of the p24-His. Panel B: Western blot from the same gel probed with an anti-6xHis mAb. Panel C: Lane 2, MAC sample probed with HIV-1 positive human sera; in lane 1, His-tagged MW marker lane was excised from the blot and probed with the anti-6xHis mAb.

\subsection{Studies on the antigenic properties of the p24-His}

We next tested the utility of the TMV-p24 HISc vector for production of useful quantities of p24-His reagent for both HIV-1 detection and immunogen utilization. It was first essential to determine if the protein maintained its antigenic properties after its expression and purification from plants. To determine this, we inoculated rabbits with recombinant protein purified from plants and assessed if the humoral immune response to recombinant $\mathrm{p} 24$-His after immunization could recognize the native p24 from HIV-1.

Production of the p24-His was scaled up by inoculating $10 N$. benthamiana plants using $\sim 5 \mu \mathrm{g}$ of RNA transcript derived from the TMV-p24-HISc vector per plant. Approximately, $25 \mathrm{~g}$ of inoculated tissue was processed and the IMAC bound protein was eluted from a column as described in Section 2. A total of $2.5 \mathrm{mg}$ of purified p24-His was eluted from the MAC column at a concentration of $0.5 \mathrm{mg}$ of $\mathrm{p} 24-$ His/ml of elution buffer, thus providing an approximated yield of $100 \mu \mathrm{g}$ of purified p24-His per gram of fresh inoculated tissue.

Animals received two immunizations with an immunogen formulated with the protein obtained from the IMAC columns without further purification. Both rabbits developed a specific humoral response against the p24-His after the second immunization, as detected by Western blot analysis against the homologous protein (data not shown) and by IFA analysis (Brayfield et al., 2003). A representative IFA experiment from the first bleed of the immunized rabbits is presented in Fig. 4. This result shows very clearly that the immune sera recognized the native HIV-1 capsid protein expressed in the infected cells, even though the HUT78/ARV cells used for the IFA were infected with an infectious clone of a clade B HIV-1 isolate. These observations suggested that: (i) despite the denaturing conditions used for elution of the protein from IMAC columns, many of the antigenic properties of the HIV-1 capsid protein were preserved in the purified p24-His
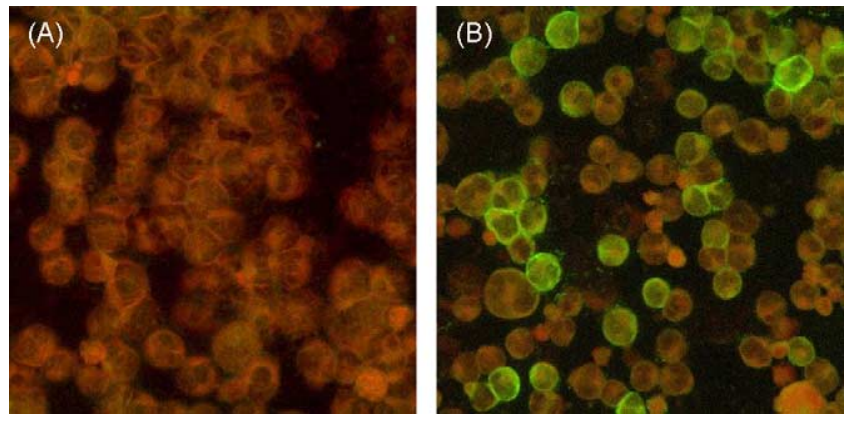

Fig. 4. Immunofluorescence assay using HUT 78/ARV cells. Panel A: Preimmune serum. Panel B: Serum from p24-His immunized rabbit at 30 days post-immunization.

and (ii) that the antibodies raised against clade $\mathrm{C}$ p24 protein can also react with native clade B p24 protein.

Finally, a subset of patients from an ongoing study of mother to child transmission of HIV-1 from Zambia were used to determine if p24-His antigen could be used in Western blot assays to confirm HIV-1 test results. In this study, commercial rapid tests (Determine ${ }^{\mathrm{TM}}$ and Capillus ${ }^{\mathrm{TM}}$ ) were used for HIV-1 serological testing at the time of delivery. A subset of patients with concordant positive $(n=70)$ and concordant negative $(n=47)$ results between the two assays, were used in Western blots. All 70 rapid test positive samples were also Western blot positive, while all those negative by the rapid tests were also negative in Western blots (Table 1).

Table 1

Use of recombinant p24-His for Western blot confirmation of HIV-1 serostatus

\begin{tabular}{lll}
\hline HIV-1 serostatus $^{\mathrm{a}}$ & Rapid tests $(+)$ & p24-His WB (+) \\
\hline Positive & 70 & 70 \\
Negative & 47 & 0 \\
\hline
\end{tabular}

${ }^{\text {a }}$ Concordant positive test results with the Capilus ${ }^{\mathrm{TM}}$ and Determine ${ }^{\mathrm{TM}}$ assays; performed according to the manufacturer. 


\section{Discussion}

Previous experience using the TMV-30B vector demonstrated that not all foreign inserts were equally stable and that the transcription of the foreign genes cloned into the vector was variable and generally decreased with increasing size of the foreign gene insert. We also encountered problems with reliable and specific immuno-detection of several animal viral proteins in the plant extracts, due to background problems resulting from cross-reactivity of the animal viral antiserum with plant proteins.

The facile production of recombinant HIV-1 structural proteins in plants is described for potential use in diagnostics as well as in vaccine production. We cloned the FMDV VP1 structural protein into the new vector TMV-30B-HISc as a model to compare it with the previously reported TMVVP1 construction (Wigdorovitz et al., 1999). The simple addition of a His-tag to the recombinant protein expressed in the well-documented TMV-30B vector provides a very useful and simple means for producing recombinant proteins in high concentrations that can be purified easily and used as diagnostic antigens or immunogens.

Both recombinant VPl-His and p24-His proteins strongly reacted against specific antisera and also against a commercially available anti-6xHis $\mathrm{mAb}$, indicating that this expression system may be a practical alternative for detecting proteins for which no specific antiserum is available. Protein purification based on the IMAC technology allowed us to achieve high product yield in one step using a relatively simple methodology. The inclusion of urea in both the extraction and elution buffers, substantially improved solubilization of proteins from total leaf extracts which may have also improved the binding specificity. The addition of urea did not noticeably affect the antigenicity of the recombinant products. This is consistent with previous reports showing that urea concentrations as high as $10 \mathrm{M}$, while increasing protein solubility, did not negatively effect the binding and haemagglutination activities of bovine rotavirus VP8* (Lee et al., 1995) or reovirus ol proteins (Yeung et al., 1987).

Application for expression of the membrane targeted HIV glycoproteins gp41 and gp120 proved less tractable. Although both recombinant products were successfully produced and detected in Western blot assays, purification yields were lower than expected since these HIV-1 glycoproteins naturally tend to remain associated to membrane structures, preventing efficient solubilization from crude plant extracts (data not shown).

Immunological analysis of the p24-His confirmed that most of the native antigenic properties were preserved in the plant-produced protein. The p24 ORF used in this study was amplified from a genomic DNA from a patient infected with HIV-1 clade C from Zambia. Our Western blot assays, using the p24-His as antigen, unambiguously confirmed $100 \%$ of the serum samples from clade C HIV-1 infected patients in a set of Zambia mothers and infants. Furthermore, in a previous report, all 44 HIV-1 mothers and infants who seroconverted during the first year after delivery, as determined by two rapid tests and IFA, were also Western blot positive using p24-His. (Brayfield et al., 2003). Importantly, antibodies induced by the p24-His were also reactive against a native p24 from a different clade (clade B), as shown in the IFA experiments. These results suggest that the recombinant $\mathrm{p} 24$-His protein has the potential for use in diagnostic testing for infection with multiple clades of HIV-1. Further testing of sera from patients infected with other HIV-1 clades and from patients comprising other HIV-1 risk groups will need to be examined to substantiate this finding.

Yields obtained for VPl-His were similar to those obtained for VP1 using the TMV-VP1 vector, reaching concentrations around $6-8 \mu \mathrm{g} / \mathrm{g}$ of fresh leaves. However, under the same experimental conditions, the amount of recombinant $\mathrm{p} 24$-His was 10-15 times higher than for VPI-His. It seems unlikely that the very high levels of recombinant p24-His observed were the result of higher accumulation of p24-His transcript as judged from previous studies which showed that transcription levels of foreign inserts in theTMV-30B vector were consistently similar for inserts of about the same size (unpublished results). These results most likely reflect the inherent stability of this protein as reported in other systems. The plant derived p24-His preparations consistently had a second band that we interpret to be a dimer of the p24-His protein. This observation had been reported previously for production of p24 in E. coli (Ehrlich et al., 1990, 1992), insect cells (Gay et al., 1998) and during in vitro assembly experiments of purified p24 (Gross et al., 1997). These studies showed that the capsid protein of HIV-1, when overexpressed, naturally tends to produce stable dimeric and oligomeric forms. We suspect, but did not confirm, that p24-His forms higher order structures in the plant tissue that makes the protein more resistant to endogenous proteases (Gross et al., 1998).

In conclusion, our results demonstrate that both the FMDV VP1 and the HIV-1 capsid antigen could be reliably produced in plants using the TMV-30B-HISc vector. Both proteins could be easily monitored in crude plant extracts using anti-His antibody and readily purified using the affinity resin. Importantly, we also show here that recombinant p24-His, purified with high yields from crude plant extracts, retained its antigenic and immunogenic properties after purification making it suitable for use as a specific diagnostic reagent and potential inclusion as a vaccine antigen. We estimate that the reagent we purified from $\sim 25 \mathrm{~g}$ of infected plant tissue could be used to conduct over $20,000 \mathrm{HIV}$ tests indicating that this technology can potentially be of great use for production of specific diagnostic reagents in resource limited areas of the world.

\section{References}

Amara, R.R., Villinger, F., Altman, J.D., Lydy, S.L., O’Neil, S.P., Staprans, S.I., Montefiori, D.C., Xu, Y., Herndon, J.G., Wyatt, L.S., Candido, M.A., Kozyr, N.L., Earl, P.L., Smith, J.M., Ma, H.L., 
Grimm, B.D., Hulsey, M.L., Miller, J., McClure, H.M., McNicholl, J.M., Moss, B., Robinson, H.L., 2001. Control of a mucosal challenge and prevention of AIDS by a multiprotein DNA/MVA vaccine. Science 292, 69-74.

Barouch, D.H., Santra, S., Kuroda, M.J., Schmitz, J.E., Plishka, R., Buckler-White, A., Gaitan, A.E., Zin, R., Nam, J.H., Wyatt, L.S., Lifton, M.A., Nickerson, C.E., Moss, B., Montefiori, D.C., Hirsch, V.M., Letvin, N.L., 2001. Reduction of simian-human immunodeficiency virus $89.6 \mathrm{P}$ viremia in rhesus monkeys by recombinant modified vaccinia virus Ankara vaccination. J. Virol. 75, 51515158.

Benson, E.M., Clarkson, J., Law, M., Marshall, P., Kelleher, A.D., Smith, D.E., Patou, G., Stewart, G.J., Cooper, D.A., French, R.A., 1999. Therapeutic vaccination with p24-VLP and zidovudine augments HIV-specific cytotoxic T lymphocyte activity in asymptomatic HFV-infected individuals. AIDS Res. Hum. Retroviruses 15, 105-113.

Brayfield, B.P., Phiri, S., Kankasa, C., Muyanga, J., Mantina, H., Kwenda, G., West, J.T., Bhat, G., Marx, D.B., Klaskala, W., Mitchell, C.D., Wood, C., 2003. Postnatal human herpesvirus-8 and human immunodeficiency virus-1 infection in mothers and infants from Zambia. Infect. Dis. 187, 559-568.

Ehrlich, L.S., Agresta, B.E., Carter, C.A., 1992. Assembly of recombinant human immunodeficiency virus type 1 capsid protein in vitro. J. Virol. 66, 4874-4883.

Ehrlich, L.S., Krausslich, H.G., Wimmer, E., Carter, C.A., 1990. Expression in Escherichia coli and purification of human immunodeficiency virus type 1 capsid protein (p24). AIDS Res. Hum. Retroviruses 6, $1169-1175$.

Gay, B., Tournier, J., Chazal, N., Carriere, C., Boulanger, P., 1998. Morphopoietic determinants of HIV-1 Gag particles assembled in baculovirus-infected cells. Virology 247, 160-169.

Giddings, G., Allison, G., Brooks, D., Carter, A., 2000. Transgenic plants as factories for biopharmaceuticals. Nat. Biotechnol. 18, 11511155.

Gross, I., Hohenberg, H., Huckhagel, C., Krausslich, H.G., 1998. Nterminal extension of human immunodeficiency virus capsid protein converts the in vitro assembly phenotype from tubular to spherical particles. J. Virol. 72, 4798-4810.

Gross, I., Hohenberg, H., Krausslich, H.G., 1997. In vitro assembly properties of purified bacterially expressed capsid proteins of human immunodeficiency virus. Eur. J. Biochem. 249, 592-600.

Johnson, J., Lin, T., Lomonosoff, G., 1997. Presentation of heterologous peptides on plant viruses: genetics, structure and function. Annu. Rev. Phytopathol. 35, 67-86.

Johnson, R.P., Trocha, A., Yang, L., Mazzara, G.P., Panicali, D.L., Buchanan, T.M., Walker, B.D., 1991. HIV-1 gag-specific cytotoxic $\mathrm{T}$ lymphocytes recognize multiple highly conserved epitopes. Fine specificity of the gag-specific response defined by using unstimulated peripheral blood mononuclear cells and cloned effector cells. J. Immunol. 147, 1512-1521.

Kusnadi, A.R., Nikolov, Z.L., Howard, J.A., 1997. Production of recombinant proteins in transgenic plants: practical considerations. Biotechnol. Bioeng. 56, 473-484.

Lacomme, C., Smolenska, L., Wilson, T.M., 1998. Genetic engineering and the expression of foreign peptides or proteins with plant virusbased vectors. In: Setlow, J.K. (Ed.), Genetic Engineering. Plenum Press, New York, pp. 225-237.

Lee, J., Babiuk, L.A., Harland, R., Gibbons, E., Elazhary, Y., Yoo, D., 1995. Immunological response to recombinant VP8* subunit protein of bovine rotavirus in pregnant cattle. J. Gen. Virol. 76, 2477-2483.

Lefrere, J.J., Courouce, A.M., Rouger, P., Duedari, N., Elghouzzi, M.H., 1992. p24 antigen and HIV screening. Lancet 339, 999-1000.

Mantina, H., Kankasa, C., Klaskala, W., Brayfield, B., Campbell, J., Du, Q., Bhat, G., Kasolo, F., Mitchell, C., Wood, C., 2001. Vertical transmission of Kaposi's sarcoma-associated herpesvirus. Int. J. Cancer 94, $749-752$.
Mason, H.S., Lam, D.M.-K., Arntzen, C.J., 1992. Expression of hepatitis B surface antigen in transgenic plants. Proc. Natl. Acad. Sci. U.S.A. 89, 11745-11749.

McCormick, A.A., Kumagai, M.H., Hanley, K., Turpen, T.H., Hakim, I., Grill, L.K., Tuse, D., Levy, S., Levy, R., 1999. Rapid production of specific vaccines for lymphoma by expression of the tumor-derived single-chain Fv epitopes in tobacco plants. Proc. Natl. Acad. Sci. U.S.A. 96, 703-708.

Nilsson, J., Stahl, S., Lundeberg, J., Uhlen, M., Nygren, P.A., 1997. Affinity fusion strategies for detection, purification, and immobilization of recombinant proteins. Protein Expr. Purif. 11, 116.

Novitsky, V., Cao, H., Rybak, N., Gilbert, P., McLane, M.F., Gaolekwe, S., Peter, T., Thior, I., Ndung'u, T., Marlink, R., Lee, T.H., Essex, M., 2002. Magnitude and frequency of cytotoxic T-lymphocyte responses: identification of immunodominant regions of human immunodeficiency virus type 1 subtype C. J. Virol. 76, 1015510168.

Pérez-Filgueira, D.M., Zamorano, P.I., Domínguez, M.G., Taboga, O.A., Del Médico Zajac, M.P., Puntel, M., Romera, S.A., Morris, T.J., Borca, M.V., Sadir, A.M., 2003. Bovine Herpes Virus gD protein produced in plants using a recombinant tobacco mosaic virus (TMV) vector possesses authentic antigenicity. Vaccine 21, 42014209.

Pogue, G., 2002. Making an ally from an enemy: plant virology and the new agriculture. Annu. Rev. Phytopathol. 40, 4574.

Shiver, J.W., Fu, T.M., Chen, L., Casimiro, D.R., Davies, M.E., Evans, R.K., Zhang, Z.Q., Simon, A.J., Trigona, W.L., Dubey, S.A., Huang, L., Harris, V.A., Long, R.S., Liang, X., Handt, L., Schleif, W.A., Zhu, L., Freed, D.C., Persaud, N.V., Guan, L., Punt, K.S., Tang, A., Chen, M., Wilson, K.A., Collins, K.B., Heidecker, G.J., Fernandez, V.R., Perry, H.C., Joyce, J.G., Grimm, K.M., Cook, J.C., Keller, P.M., Kresock, D.S., Mach, H., Troutman, R.D., Isopi, L.A., Williams, D.M., Xu, Z., Bohannon, K.E., Volkin, D.B., Montefiori, D.C., Miura, A., Krivulka, G.R., Lifton, M.A., Kuroda, M.J., Schmitz, J.E., Letvin, N.L., Caulfield, M.J., Bett, A.J., Youil, R., Kaslow, D.C., Emini, E.A., 2002. Replication-incompetent adenoviral vaccine vector elicits effective anti-immunodeficiency-virus immunity. Nature 415, 331335

Shivprasad, S., Pogue, G.P., Lewandowski, D.J., Hidalgo, J., Donson, J., Grill, L.K., Dawson, W.O., 1999. Heterologous sequences greatly affect foreign gene expression in tobacco mosaic virus-based vectors. Virology 255, 312-323.

Siegel, A., Hari, V., Kolacz, K., 1978. The effect of tobacco mosaic virus infection and virus-specific protein synthesis in protoplast. Virology $85,494-502$.

Toth, R., Pogue, G., Chapman, S., 2002. Improvement of the movement and host range properties of a plant virus vector through DNA shuffling. Plant J. 30, 593-600.

Walmsley, A.M., Arntzen, C.J., 2000. Plants for delivery of edible vaccines. Curr. Opin. Biotechnol. 11, 126-129.

Walmsley, A.M., Arntzen, C.J., 2003. Plant cell factories and mucosal vaccines. Curr. Opin. Biotechnol. 14, 145-150.

Wigdorovitz, A., Pérez-Filgueira, D.M., Robertson, N., Carrillo, C., Sadir, A.M., Morris, T.J., Borca, M.V., 1999. Protection of mice against challenge with foot and mouth disease virus (FMDV) by immunization with foliar extracts from plants infected with recombinant tobacco mosaic virus expressing the FMDV structural protein VP1. Virology 264, 85-91.

Yeung, M.C., Gill, M.J., Alibhai, S.S., Shahrabadi, M.S., Lee, P.W., 1987. Purification and characterization of the reovirus cell attachment protein sigma 1 . Virology 156, 377-385.

Yusibov, V., Shivprasad, S., Turpen, T.H., Dawson, W., Koprowski, H., 1999. Plant viral vectors based on tobamoviruses. Curr. Top. Microbiol. Immunol. 240, 81-94. 
Zamorano, P.I., Wigdorovitz, A., Fernandez, F.M., Chaer, M., Marcovecchio, F.E., Carrillo, C., Sadir, A.M., Borca, M.V., 1994. Recognition of $\mathrm{T}$ and $\mathrm{B}$ epitopes by cattle immunized with a synthetic peptide containing the major immunogenic area of FMDV O1 Campos VP1. Virology 201, 383387.
Zhang, G., Leung, C., Murdin, L., Rovinski, B., White, A., 2000. In planta expression of HIV-1 p24 protein using an RNA plant virusbased expression vector. Molec. Biotechnol. 14, 99-107.

Zhang, G., Rodrigues, L., Rovinski, B., White, A., 2002. Production of HIV-1 p24 protein in transgenic tobacco plants. Molec. Biotechnol. 20, 131-136. 